\title{
Expression of Th1- Th2- and Th17-associated cytokines in laryngeal carcinoma
}

\author{
XIAOQUN XU ${ }^{1}$, RUI WANG ${ }^{2}$, QINGHONG SU ${ }^{1}$, HAIYAN HUANG $^{1}$, PENG ZHOU ${ }^{1}$, \\ JUNWEN LUAN $^{1}$, JINGSHENG LIU ${ }^{1}$, JUNFU WANG ${ }^{1}$ and XUEMEI CHEN ${ }^{3}$ \\ ${ }^{1}$ Institute of Basic Medicine, Shandong Academy of Medical Sciences, Jinan, \\ Shandong 250062; ${ }^{2}$ Department of Neurosurgery, Heze Municipal Hospital, Heze, Shandong 274000; \\ ${ }^{3}$ Department of Otolaryngology, The Second Hospital of Shandong University, Jinan, Shandong 250033, P.R. China
}

Received March 31, 2015; Accepted May 26, 2016

DOI: $10.3892 / 01.2016 .4854$

\begin{abstract}
T-helper (Th) 0 cell differentiation into Th1 or Th2 cells is dependent on a number of transcription factors that act at specific time points to regulate gene expression. Th17 cells, a subset of interleukin (IL)-17-producing T cells distinct from Th1 or Th2 cells, are considered to exhibit a critical function in inflammation and autoimmune diseases, as well as cancer development. In the present study, the expression of Th1-, Th2- and Th17-associated cytokines in laryngeal cancer and pericarcinoma tissues obtained from 57 laryngeal carcinoma patients was investigated. The association between Th1, Th2 and Th17 infiltration and tumor development was also evaluated. Reverse transcription-polymerase chain reaction and western blotting results revealed that the mRNA and protein expression of Th2 cytokines was lower, while the expression of Th1 and Th17 cytokines was higher in tumor tissues than in pericarcinoma tissues. Furthermore, the early stage cancer patients exhibited a higher level of interferon- $\gamma$, IL-2 and IL-17 mRNA expression than those at advanced stages. Cancer tissues exhibited higher Th17 cytokine expression than pericarcinoma tissues. By contrast, Th1 cytokine expression was increased in pericarcinoma tissues compared with cancer tissues. These results indicate that high expression of Th1- and Th17-associated cytokines in laryngeal carcinoma may contribute to suppression of cancer development and a relatively good prognosis.
\end{abstract}

Correspondence to: Professor Junfu Wang, Institute of Basic Medicine, Shandong Academy of Medical Sciences, 18877 Jingshi Road, Jinan, Shandong 250062, P.R. China

E-mail:wjf_1030@126.com

Professor Xuemei Chen, Department of Otolaryngology, The Second Hospital of Shandong University, 247 Beiyuan Avenue, Jinan, Shandong 250033, P.R. China

E-mail: chxmsd@163.com

Key words: laryngeal carcinoma, T-helper 1, T-helper 2, T-helper 17, cytokine

\section{Introduction}

Cancer progression is a complex process that involves host-tumor interactions, which occur via multiple molecular and cellular factors within the tumor microenvironment (1). Previous findings have shown that inflammation contributes to the proliferation, migration and survival of cancer cells, which may lead to tumor invasion and metastasis (2-5). However, inflammation in the tumor microenvironment is an important component of the tumor-associated immune response. Inflammatory cells and molecules may function to initiate and maintain tumor immunity (6,7). Cluster of differentiation (CD) $4^{+}$T-helper (Th) cells, as a highly heterogenic and plastic population, exhibit a critical function in tumor immunological responses (8). CD4 ${ }^{+}$Th cells are classified into 4 subtypes, Th1, Th2, Th17 and T regulatory (T reg) cells, according to their distinct cytokine repertoire, which governs the overall immune response via an intricate network (9). Th1 cells produce interferon (IFN) $\gamma$, interleukin (IL)-2, IL-12 and tumor necrosis factor $\alpha$ cytokines, which are involved in the cell-mediated pro-inflammatory response. Th1-associated cytokines exhibit potent anti-tumor effects by activating $\mathrm{CD}^{+}$ cytotoxic $\mathrm{T}$ lymphocytes and natural killer (NK)-mediated cytotoxicity, as well as upregulating major histocompatibility complex expression on antigen presenting cells. Conversely, $\mathrm{Th} 2$ cells secrete IL-4, IL-5, IL-6, IL-10 and IL-13 cytokines, which mediate anti-inflammatory humoral response and immune suppression via the inhibition of Th1 cytokine production (10). Th17 cells are characterized as IL-17-producing $\mathrm{CD}^{+}{ }^{+} \mathrm{T}$ cells, which also produce IL-21, -22 and -26 $(11,12)$. It has been demonstrated that the retinoid orphan nuclear receptor is a key regulator of Th17 cell lineage differentiation (13). Furthermore, Th17 cells are hypothesized to exhibit a critical function in the development of autoimmunity and allergic reactions $(14,15)$. TGF $\beta 1$, a member of the TGF $\beta$ family that is predominantly secreted by Tregs, is another multi-functional cytokine. It promotes tumor progression by inducing mesenchymal transition, tumor escape by antagonizing IL-2 functions and inducing immune suppression $(16,17)$, tumor invasion and metastasis (18).

Laryngeal cancer represents one of the most common head and neck malignancies, accounting for $\sim 20 \%$ of all cases. The vast majority of tumors are squamous cell carcinomas (19). Up to $40 \%$ of patients present with advanced disease. Due to 
the important physiological functions of the larynx, advanced laryngeal lesions are associated with significant morbidity and mortality for the patient and increased financial costs for society $(20,21)$. When patients experience postoperative recurrence and/or distant metastasis, it is not sensitive to radiation and chemotherapy. This results in a poor prognosis (22).

In the present study, the mRNA and protein expression of Th1-, Th2- and Th17-associated cytokines was analyzed at the tissue level by reverse transcription-polymerase chain reactions (RT-PCR) and western blot analysis to investigate the function and clinical significance of Th1, Th2 and Th17 cells in laryngeal carcinoma and their involvement in laryngeal carcinoma pathogenesis.

\section{Materials and methods}

Patients. The present study included 57 patients with a mean age of 54.2 \pm 10.25 years (range, 37-73 years) who were histologically diagnosed with laryngeal carcinoma and 7 throat injury patients, with a mean age of $45.1 \pm 10.35$ years (range, 32-61 years), that served as age- and gender-matched controls. The patients were recruited at The Second Hospital of Shandong University (Jinan, China) between March 2011 and December 2014. Fresh surgical specimens were collected from patients undergoing surgery for different stages of squamous carcinoma of the larynx. Tumors were staged in accordance with the American Joint Committee on Cancer tumor-node metastasis (TNM) classification (23). None of the patients had received chemotherapy, radiation therapy or immunotherapy in the 2 months prior to surgery. Control non-neoplastic tissues consisted of samples ( 1x1x2 mm sections) from the irregular mucosal edge obtained during tissue repair of the larynx and hypopharynx of the throat injury patients. Cancer tissues and pericancerous tissues were identified by stereoscopy and quick frozen sectioning. Two tissue sections were collected from each patient and snap-frozen for RNA extraction and protein preparation, respectively. Patients presenting with any other chronic disease, such as diabetes, tuberculosis, other malignancies or autoimmune disease at the time of specimen collection were excluded. Similarly, normal controls that had presented with fever or viral infection in the week prior to surgery, were pregnant or had been involved in a recent accident were also excluded from the study.

The protocol of the present study was approved by the Ethics Committee of Shandong University School of Medicine and all participants provided written informed consent. Representative samples of tumors from the larngeal cancer patients and normal control tissues from teh patients with laryngeal trauma were obtained during surgery. The samples were snap-frozen immediately in Eppendorf tubes $(1.5 \mathrm{ml})$ and stored at $-80^{\circ} \mathrm{C}$ to avoid RNA and protein degradation prior to sectioning for RT-PCR and western blot analysis.

Reagents. The total RNA extraction kit (Transgen Biotech Co., Beijing, China) was prepared at The Second Hospital of Shandong University. M-MLV reverse transcriptase and Taq DNA polymerase were purchased from Promega Corporation (Madison, WI, USA). PCR primers (BioSune Biotechnology Corporation, Shanghai, China) for the detection of IFN- $\gamma$, IL-2, IL-4, IL-6, IL-10, IL-17A and $\beta$-actin mRNA were designed using the OLIGO Primer Analysis Software, version 5.0 (NBA,
Software and Research Services for Tomorrow's Discoveries, National Biosciences, Plymouth, MN, USA). The PCR oligomers were synthesized using a DNA/RNA synthesizer (Applied Biosystems; Thermo Fisher Scientific, Inc., Waltham, MA, USA) at BioSune Biotechnology Corporation. Primer sequences are listed in Table I. Mouse anti-human IFN- $\gamma$ monoclonal antibody (catalog no. sc-47700; dilution, 1:200), mouse anti-human IL-4 monoclonal antibody (catalog no. sc-13555; dilution, 1:200), mouse anti-human IL-17 monoclonal antibody (catalog no. sc-374218; dilution, 1:200) and rabbit $\beta$-actin polyclonal antibody (catalog no. sc-1616; dilution, 1:200) were purchased from Santa Cruz Biotechnology, Inc. (Santa Cruz, CA, USA). Horseradish peroxidase-labeled goat anti-mouse (catalog no. ZB2305; dilution, 1:5,000) and anti-rabbit IgG (catalog no. ZB2301; dilution, 1:5,000) secondary antibodies were purchased from Zhongshan Golden Bridge Biotechnology Co., Ltd. (Beijing, China).

$R T-P C R$. RT-PCR was performed as described previously (24). Briefly, RNA was extracted from tissues using the guanidine thiocyanate phenol-chloroform method (25). The quality of the RNA yield was assessed by electrophoresis on a $1.5 \%$ agarose gel in $0.5 \mathrm{~mol}$ Tris/Borate/EDTA buffer. The optical density of the RNA samples was measured by microplate reader (Thermo Fisher Scientific Inc.) and samples exhibiting an A260-A280 ratio of 1.8-2.0 were used to obtain cDNA. RT-PCR was performed using a RNA PCR kit (Perkin-Elmer, Norwalk, CT, USA). Cellular RNA ( $1 \mu \mathrm{g})$ was reverse-transcribed into cDNA in a reaction mixture containing $5 \mathrm{mmol} \mathrm{MgCl}_{2}, 1 \mathrm{mmol} \mathrm{dNTP}$, $2.5 \mu \mathrm{mol}$ oligo (dT) primer, 1 unit RNase inhibitor and 200 units reverse transcriptase (M-MLV). Following incubation at $37^{\circ} \mathrm{C}$ for $60 \mathrm{~min}$, the reaction was terminated by heating at $95^{\circ} \mathrm{C}$ for $5 \mathrm{~min}$. PCR was performed using the forward and reverse primers listed in Table I. The PCR reaction buffer $(25 \mu \mathrm{l})$ consisted of $2 \mathrm{mmol}$ $\mathrm{MgCl}_{2}, 0.5 \mu \mathrm{mol}$ of each primer, 1 unit Taq DNA polymerase and $5 \mu \mathrm{l}$ reverse-transcription product. PCR was performed under the following conditions: Initial denatureation at $95^{\circ} \mathrm{C}$ for $5 \mathrm{~min}$, then 33 cycles of $95^{\circ} \mathrm{C}$ for $1 \mathrm{~min}, 58^{\circ} \mathrm{C}$ for $1 \mathrm{~min}$ and $72^{\circ} \mathrm{C}$ for $1 \mathrm{~min}$. Aliquots $(15 \mu \mathrm{l})$ of the amplified product were then fractionated on a $1.5 \%$ agarose gel and visualized by ethidium bromide staining. The band intensity of ethidium bromide fluorescence was measured using NIH/1D Image Analysis Software 1.61 (National Institutes of Health, Bethesda, MD, USA). The relative intensity $(\mathrm{RI})$ of each band was determined according to the following equation: RI = density of target gene/density of $\beta$-actin. To exclude the possibility of contamination, reactions containing RT-PCR reagents including cytokine PCR primers without sample RNA were used as the negative control groups.

Western blot analysis. SDS-PAGE and immunoblotting were performed according to standard techniques (24). Briefly, the prepared tissues were lysed at $4^{\circ} \mathrm{C}$ for $30 \mathrm{~min}$ in lysis buffer [20 mmol Tris-HCl (pH 7.5), 1\% Nonidet P-40, $150 \mathrm{mmol}$ $\mathrm{NaCl}, 1 \mathrm{mmol}$ ethylenediamine tetraacetic acid, $50 \mathrm{U} / \mathrm{ml}$ aprotinin, $1 \mathrm{mmol}$ phenylmethylsulfonyl fluoride and $1 \mathrm{mmol}$ sodium orthovanadate; Beijing Leagene Biotech. Co., Ltd., Beijing, China]. The lysates were centrifuged at 21,100 x g for $20 \mathrm{~min}$ at $4^{\circ} \mathrm{C}$ to remove nuclei and undisrupted tissues. Protein concentration was determined using Bio-Rad protein assay solution (Bio-Rad Laboratories, Inc., Hercules, CA, 
Table I. Primer sequences of Th1-, Th2- and Th17-associated cytokines used for reverse transcription-polymerase chain reaction in the present study.

\begin{tabular}{|c|c|c|}
\hline Target gene & Oligonucleotide sequence & $\begin{array}{l}\text { Product } \\
\text { size (bp) }\end{array}$ \\
\hline IFN- $\gamma$ & $\begin{array}{l}\text { (F) 5'-ATGAAATATACAAGTTATATCTTGGCTTT-3' } \\
\text { (R) 5'-GATGCTCTTCGACCTCGAAACAGCAT-3' }\end{array}$ & 494 \\
\hline IL-2 & $\begin{array}{l}\text { (F) 5'-ATGTACAGGATGCAACTCCTGTCTT-3' } \\
\text { (R) 5'-GTTAGTGTTGAGATGATGCTTTGAC-3' }\end{array}$ & 458 \\
\hline IL-4 & $\begin{array}{l}\text { (F) 5'-ATGGGTCTCACCTCCCAACTGCT-3' } \\
\text { (R) 5'-CGAACACTTTGAATATTTCTCTCTCTCAT-3' }\end{array}$ & 456 \\
\hline IL-6 & $\begin{array}{l}\text { (F) 5'-CCGAATTCATGATTGACAAACAAATTCCGG-3' } \\
\text { (R) 5'-CGCGGATCCTTACATTTGCCGAAGAG-3' }\end{array}$ & 531 \\
\hline IL-10 & $\begin{array}{l}\text { (F) 5'-ATGCCCCAAGCTGAGAACCAAGACCCA-3' } \\
\text { (R) 5'-GTTTCGTATCTTCATTGTCAT-3' }\end{array}$ & 249 \\
\hline IL-17A & $\begin{array}{l}\text { (F) 5'-AGAGATATCCCTCTGTGATC-3' } \\
\text { (R) 5'-TACCCCAAAGTTATCTCAGG-3' }\end{array}$ & 519 \\
\hline$\beta$-actin & $\begin{array}{l}\text { (F) 5'-GTGGGCGCCCAGGCACCA-3' } \\
\text { (R) 5'-CTCCTTAATGTCACGCACGATTT-3' }\end{array}$ & 539 \\
\hline
\end{tabular}

Th, T-helper; IFN, interferon; IL, interleukin; (F), forward primer; (R), reverse primer; bp, base pairs.

USA) with bovine serum albumin as the standard (24,26). The protein samples were boiled for $10 \mathrm{~min}$ and loaded onto a $14 \%$ SDS-PAGE gel followed by electrophoresis for $2 \mathrm{~h}$. The proteins were electrophoretically transferred onto a $0.22 \mu \mathrm{m}$ nitrocellulose membrane and immunoblotted with monoclonal mouse anti-human IFN- $\gamma$, IL-4, IL-17 and polyclonal rabbit $\beta$-actin primary antibodies (Santa Cruz Biotechnology, Inc.). After the membrane was washed three times at 5-min intervals in phosphate-buffered saline-Tween 20 (PBS-T), the membrane was subsequently incubated with goat anti-mouse IgG-horseradish peroxidase (HRP) or goat anti-rabbit IgG-HRP (Zhongshan Golden Bridge Biotechnology Co., Ltd.) diluted to 1:5,000 for $1 \mathrm{~h}$ at room temperature. After the membrane was washed three times at 5-min intervals in PBS-T, the immunoblots were then visualized using an ImageQuant LAS 4000 chemiluminescence imager (GE Healthcare, Piscataway, NJ, USA).

Statistical analysis. To determine the levels of Th1, Th2 and Th17 cells in laryngeal carcinoma, data analysis was performed using SPSS 11.5 statistical software (SPSS, Inc., Chicago, IL, USA). Data were presented as the mean \pm standard deviation. The paired samples t-test was used to compare differences between laryngeal carcinoma and pericarcinoma tissues. One-way analysis of variance analysis was used to compare the differences between groups at different clinical stages. $\mathrm{P}<0.05$ was considered to indicate a statistically significant difference.

\section{Results}

Patient clinicopathological characteristics. The clinicopathological characteristics of the patient cohort, which included 57 laryngeal carcinoma patients and 7 healthy controls (6 male and 1 female) are shown in Table II. Of the 57 laryngeal carcinoma patients, $54(94.7 \%)$ were male and $3(5.3 \%)$ were female
Table II. Clinicopathological characteristics of laryngeal carcinoma patients and controls.

Clinicopathological

characteristics

Patients, n (\%) Control,n (\%)

\begin{tabular}{llc}
\hline Age, years & & \\
Range & $37-73$ & $32-61$ \\
Mean \pm SD & $54.2 \pm 10.25$ & $45.1 \pm 10.35$ \\
Gender & & \\
Male & $54(94.7)$ & 6 \\
Female & $3(5.3)$ & 1 \\
Tumor size & & \\
T1+T2 & $19(33.3)$ & \\
T3 & $26(45.6)$ & \\
T4 & $12(21.1)$ & \\
Lymph node involvement & & \\
N0 & $14(24.6)$ \\
N+ & $53(75.4)$ \\
Pathological classification & \\
Squamous cell carcinoma & $57(100.0)$ \\
Histological classification & \\
Well-differentiated & $17(29.8)$ \\
Moderately-differentiated & $28(49.1)$ \\
Poorly-differentiated & $12(21.1)$ \\
Clinical stage & \\
I+II & $20(35.1)$ \\
III & $22(38.6)$ \\
IV & $15(26.3)$ \\
\end{tabular}

$\mathrm{SD}$, standard deviation. 

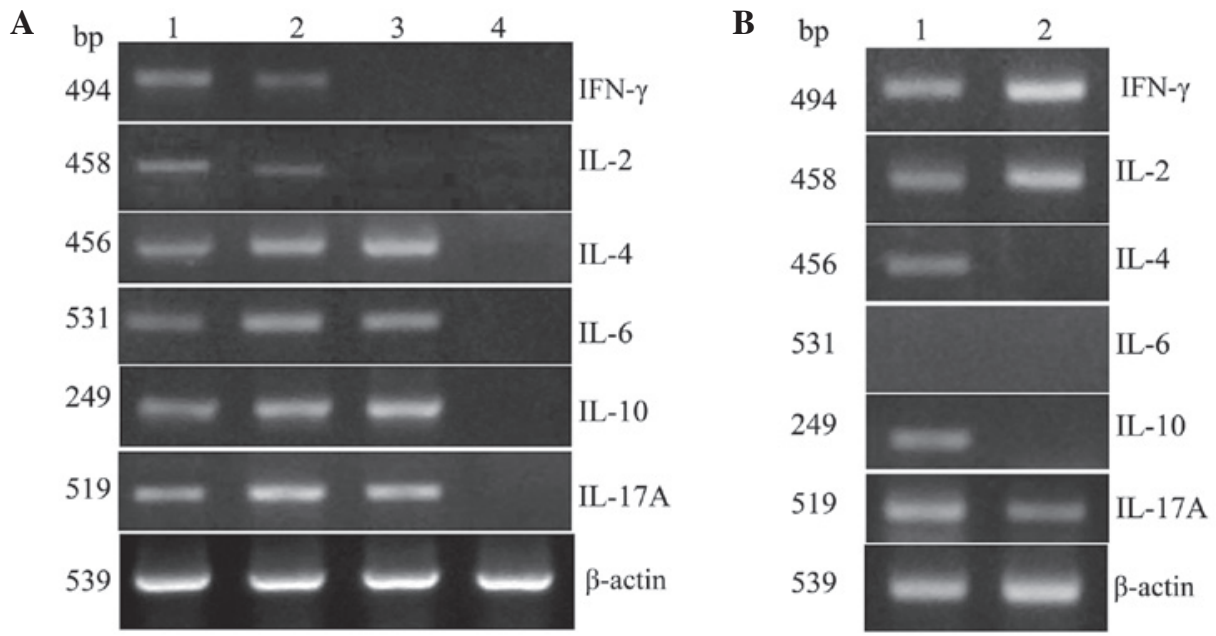

Figure 1. mRNA expression of Th1, Th2 and Th17-associated cytokines in fresh tumor tissues and pericarcinoma tissues obtained from laryngeal carcinoma patients. (A) Representative mRNA expression of Th1-, Th2- and Th17-associated cytokines in tumor tissues of different clinical stages and in normal control tissues. The Th1-associated cytokine expression (IFN- $\gamma$ and IL-2) was decreased with increasing clinical stage. The mRNA expression of Th2-associated cytokines (IL-4, IL-6 and IL-10) was enhanced with increasing clinical stage. Th17-associated cytokine (IL-17A) exhibited a high level of expression, and early clinical stage patients had a lower level of IL-17A mRNA expression than those at an advanced clinical stage. There was no expression of Th1-, Th2- and Th17-associated cytokines in the normal control tissues (lane 1, stage I + II patient; lane 2, stage III patient; lane3, stage IV patient; lane 4, normal control). (B) Representative mRNA expression of Th1-, Th2- and Th1-associated cytokines in tumor tissues and pericarcinoma tissues. The expression of Th1 cytokines was higher than Th2- and Th17-associated cytokines in tumor tissues. The expression of Th2 cytokines in tumor tissues and pericarcinoma tissues was low, however, the expression was higher in tumor tissues than pericarcinoma tissues. Th17-associated cytokine expression was higher in tumor tissues than pericarcinoma tissues (lane 1, tumor tissue; lane 2, pericarcinoma tissue). Th, T-helper; IFN, interferon; IL, interleukin.

(gender ratio, 18:1). In accordance with TNM classification, the majority of patients presented with large tumors $(\mathrm{T} 3+\mathrm{T} 4$ $66.7 \%)$ and lymph node involvement $(\mathrm{N}+; 75.4 \%)$. The majority of patients exhibited advanced stage disease (stage III + IV; $64.9 \%$ ), while $35.1 \%$ exhibited early stage cancer (stage I \pm II). All the patients were pathologically diagnosed with squamous cell carcinoma. Histologically, $70.2 \%$ of patients exhibited poorly- or moderately-differentiated tumors.

Th1-associated cytokine expression is dominant in laryngeal carcinoma. Total RNA of 57 fresh tissues obtained from laryngeal carcinoma patients and 7 mucosal laryngeal tissues obtained from throat injury control patients were prepared. The mRNA cytokine expression profiles from the aforementioned tissues were analyzed by RT-PCR. In the control tissues no lymphomononuclear infiltrates and extremely low expression levels of Th1-, Th2- or Th17-associated cytokines were identified (Fig. 1).

The mRNA tissue expression of the Th1-associated cytokines, IFN- $\gamma$ and IL-2, was analyzed. The relative intensity of Th1-associated cytokine expression was relatively high in laryngeal carcinoma patients (Figs. 1-3). Of the 57 laryngeal carcinoma patients, 34 cancer tissues $(59.6 \%)$ and 38 pericarcinoma tissues $(66.7 \%)$ expressed IFN $-\gamma$ mRNA (RI, 0.296 \pm 0.264 and $0.318 \pm 0.249$, respectively; $t=1.542$; $\mathrm{P}=0.129)$ and 33 cancer tissues $(57.9 \%)$ and 37 pericarcinoma tissues (64.9\%) expressed IL-2 mRNA (RI, $0.283 \pm 0.262$ and $0.309 \pm 0.251$, respectively; $\mathrm{t}=2.025 ; \mathrm{P}=0.048$ ). It was found that the expression of Th1-associated cytokines was dominant in laryngeal carcinoma when compared with Th2- and Th17-associated cytokines. Early stage laryngeal carcinoma patients exhibited significantly higher levels of IFN- $\gamma$ $(\mathrm{F}=8.868 ; \mathrm{P}<0.01)$ and $\mathrm{IL}-2(\mathrm{~F}=4.315 ; \mathrm{P}<0.01)$ mRNA expression than those at advanced stages. Cancer tissues exhibited a lower level of IFN- $\gamma$ mRNA expression than pericarcinoma tissues, however this difference was not statistically significant. Cancer tissues exhibited a significantly lower level of IL-2 mRNA expression than pericarcinoma tissues $(\mathrm{P}<0.05)$.

Th2-associated cytokines are expressed at low levels in laryngeal carcinoma. The mRNA tissue expression of Th2-associated cytokines, IL-4, IL-6 and IL-10, was analyzed. The expression levels of Th2-associated cytokines were relatively low in laryngeal carcinoma patients (Figs. 1-3). Of the 57 laryngeal carcinoma patients, 14 cancer tissues (24.6\%) and 12 pericarcinoma tissues (21.1\%) expressed IL-4 mRNA (RI, $0.088 \pm 0.159$ and $0.076 \pm 0.151$, respectively; $\mathrm{t}=1.516$; $\mathrm{P}=0.135), 12$ cancer tissues (21.1\%) and 12 pericarcinoma tissues (21.1\%) expressed IL-6 mRNA (RI, 0.071 \pm 0141 and $0.068 \pm 0.137$, respectively; $\mathrm{t}=1.316 ; \mathrm{P}=0.194)$ and 19 cancer tissues (33.3\%) and 17 pericarcinoma tissues $(29.8 \%)$ expressed IL-10 mRNA (RI, $0.121 \pm 0.177$ and $0.106 \pm 0.169$, respectively; $\mathrm{t}=1.577 ; \mathrm{P}=0.120)$. The expression of Th2-associated cytokines increased with clinical stage. Notably, IL-4 expression was significantly higher in stage IV patients compared with stage I + II patients $(\mathrm{P}<0.05)$. Furthermore, IL-4, IL-6 and IL-10 mRNA expression in cancer tissues was higher than that in pericarcinoma tissues, although no significant differences were identified.

Th17-associated cytokine IL-17A is predominantly expressed in laryngeal carcinoma. The mRNA tissue expression of the Th17-associated cytokine, IL-17A, was analyzed. The expressing capacity of patients for Th17 cytokines was superior overall when compared with the other cytokines (Figs. 1-3). Of the 57 laryngeal carcinoma patients, 45 cancer tissues (78.9\%) and 40 pericarcinoma tissues (70.2\%) expressed IL-17A mRNA (RI, $0.283 \pm 0.181$ and $0.235 \pm 0.181$, respectively; $\mathrm{t}=2.763$; 


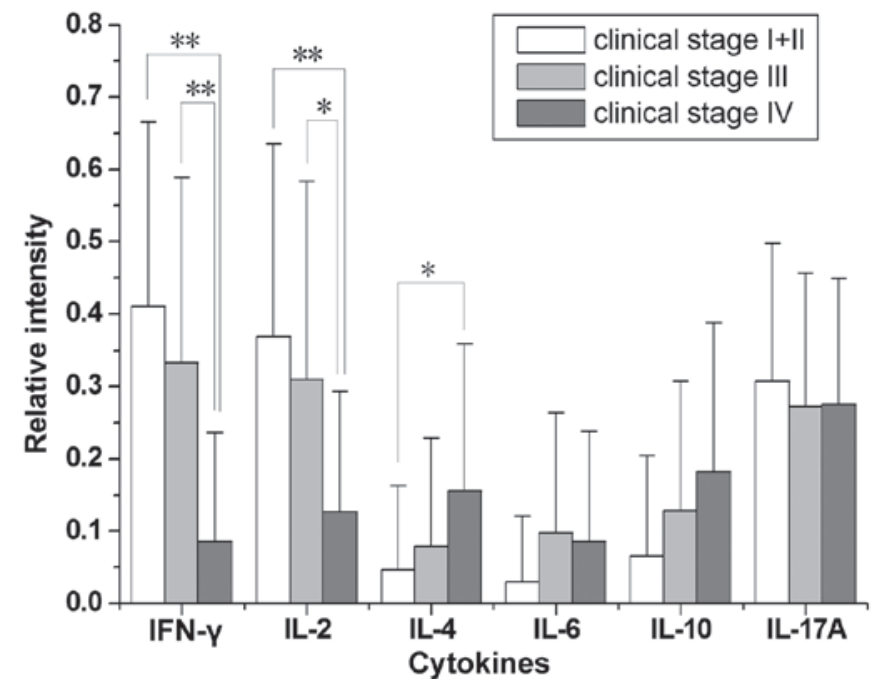

Figure 2. Relative intensity of Th1-, Th2- and Th17-associated cytokine mRNA expression in laryngeal carcinoma tissues. Th1 cytokines (IFN- $\gamma$ and IL-2) and Th17 (IL-17A) exhibited the highest levels of expression. Early stage patients exhibited higher levels of IFN- $\gamma$, IL-2 and IL-17A mRNA expression than advanced stage patients. In particular, the mRNA expression of IFN- $\gamma$ and IL-2 in stage I + II laryngeal carcinoma patients was significantly higher than that of stage IV laryngeal carcinoma patients. Th2 cytokines (IL-4, IL-6 and IL-10) were expressed at low levels. The intensity of expression of Th2-associated cytokines was lower in early stage patients compared with advanced stage patients. ${ }^{*} \mathrm{P}<0.05$ and ${ }^{* *} \mathrm{P}<0.01$. Th, T-helper; IFN, interferon; IL, interleukin.

$\mathrm{P}=0.008)$. Furthermore, patients with early stage laryngeal carcinoma exhibited a lower level of IL-17A mRNA expression than those at advanced stages. Cancer tissues exhibited a significantly higher level of IL-17A mRNA expression than pericarcinoma tissues $(\mathrm{P}<0.05)$.

Immunoblotting revealed the protein expression levels of associated cytokines in laryngeal carcinoma. The protein expression of Th1-, Th2- and Th17-associated cytokines was analyzed by western blot analysis. IFN- $\gamma$, IL-4 and IL-17 were considered to be Th1-, Th2- and Th17-associated cytokines, respectively. No significant differences were identified between the protein expression of IFN- $\gamma$, IL-4 and IL-17A in laryngeal carcinoma and pericarcinoma tissues. Almost no IFN- $\gamma$, IL- 4 and IL-17 protein expression was identified in the normal control tissues. IFN- $\gamma$ expression was the highest in laryngeal carcinoma tissues in comparison with IL-4 and IL-17A. IFN- $\gamma$ expression was higher in early stage $(\mathrm{I}+\mathrm{II})$ patients than advanced stage (III + IV) patients. Notably, the expression of IFN- $\gamma$ was lower in the cancer tissues than the pericarcinoma tissues. IL-4 expression was extremely low in laryngeal carcinoma and pericarcinoma tissues, whereas IL-17 expression was extremely high in laryngeal carcinoma tissues. Furthermore, the expression of IL-17 was higher in early stage patients compared with advanced stage patients. The expression of IL-4 and IL-17 in cancer tissues was higher than that in the pericarcinoma tissues (Fig. 4).

\section{Discussion}

Head and neck tumors are a significant cause of mortality and are ranked as the sixth most common type of cancer,

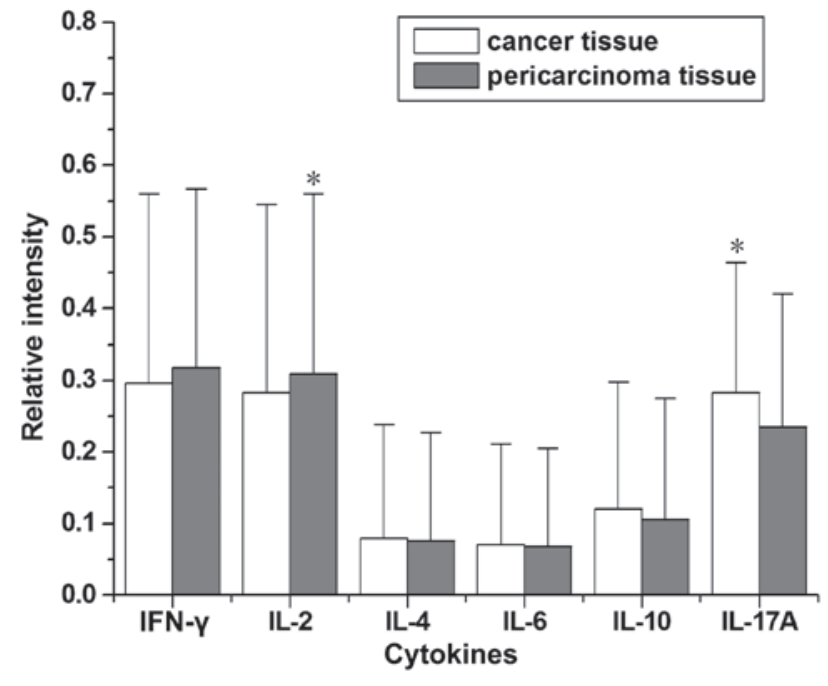

Figure 3. Relative intensity of Th1-, Th2- and Th17-associated cytokine mRNA expression in laryngeal carcinoma tissues and pericarcinoma tissues. Th1 cytokines (IFN- $\gamma$ and IL-2) and Th17 (IL-17A) exhibited the highest levels of expression. The intensity of IL-17A expression was higher in laryngeal carcinoma tissues than pericarcinoma tissues. The intensity of IFN- $\gamma$ and IL-2 expression was lower in laryngeal carcinoma tissues than in pericarcinoma tissues. The expression of IL-2 was significantly higher in pericarcinoma tissue compared with laryngeal carcinoma tissue. IL-17A expression was significantly higher in laryngeal carcinoma tissues than in pericarcinoma tissues. Th2 cytokines (IL-4, IL-6 and IL-10) exhibited low expression in both tissues. ${ }^{*} \mathrm{P}<0.05$. Th, T-helper; IFN, interferon; IL, interleukin.

worldwide (27). Laryngeal carcinoma is one of the most common types of head and neck tumor and is the second most prevalent tumor of the respiratory tract (22). Of all the laryngeal tumors, squamous cell carcinoma is extremely common, with an incidence that has been on the increase, from 0.5 to 2.04 cases per millions individuals in recent years, particularly during the era of rapid industrialization in China $(28,29)$. Despite novel surgical procedures, chemotherapeutic drugs and advances in the field of radiotherapy over the past 30 years, the overall survival rate of laryngeal carcinoma patients has remained at $\sim 67 \%(30,31)$. Smoking, alcohol consumption, air pollution and certain occupational factors are considered to be epidemiologically-related factors of the disease $(32,33)$. In the present study, all the patients were diagnosed with squamous cell carcinoma and $75.4 \%$ patients exhibited lymph node metastasis. A total of $64.9 \%$ of patients exhibited advanced stage (III + IV) disease and $70.2 \%$ of patients exhibited moderately-or poorly-differentiated tumors. The tumor classification of the patients in the present study was consistent with the literature reported previously (22).

Accumulating evidence has altered the traditional paradigm of Th1/Th2 cytokine classification to include two novel subsets of $\mathrm{CD}^{+} \mathrm{T}$ cells, Th17 and Treg cells, which are characterized by their distinct cytokine profiles (34-36). Th17 and Treg cells predominantly produce IL-17 and TGF $\beta$ family cytokines, respectively (37). These cytokines, in combination with other molecules (such as IL-21, IL-23, ROR $\gamma \mathrm{t}$ and Fox-P3) are involved in a complex, tightly-regulated network that controls immune function. Disruption of this network may lead to immune dysfunction, uncontrolled cell growth, chronic inflammation and ultimately carcinogenesis (16). In the present study, the delicate balance between the three 
A

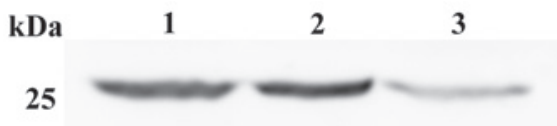

4

18

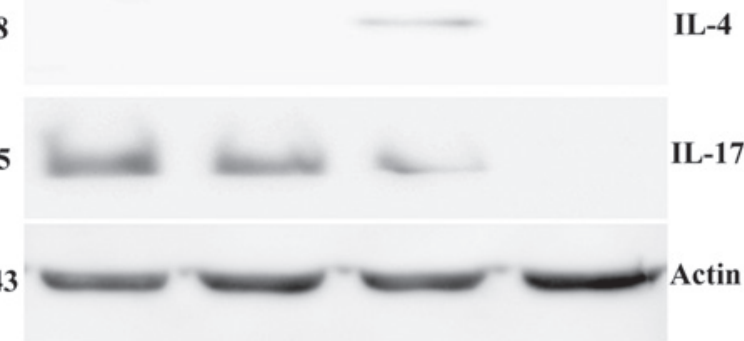

IFN- $\gamma$

IL-4

IL-17

Actin
B

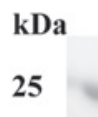

1

2

IFN- $\gamma$

18

IL-4

15

IL-17

43

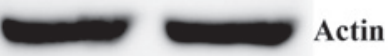

Figure 4. Protein expression of IFN- $\gamma$, IL-4 and IL-17 in fresh tumor tissues and pericarcinoma tissues obtained from laryngeal carcinoma patients. (A) Representative protein expression of IFN- $\gamma$, IL-4 and IL-17 in tumor tissues of different clinical stages and normal control tissues. IL-4 expression was lowest when compared with IFN- $\gamma$ and IL-17 expression, and no IL-4 expression was observed in stage I-III tissues. Patients at the early stage of disease exhibited higher levels of IFN- $\gamma$ and IL-17 protein expression than those at advanced stages. No IFN- $\gamma$, IL-4 or IL-17 protein expression was identified in normal control tissues. (Lane 1, stage I \pm II tissue; lane 2, stage III tissue; lane 3, stage IV tissue; lane 4, normal control tissue). (B) Representative IFN- $\gamma$, IL-4 and IL-17 protein expression in tumor and pericarcinoma tissues. IFN- $\gamma$ protein expression was higher in pericarcinoma tissue than carcinoma tissues. IL-17 protein expression was higher in carcinoma tissues than pericarcinoma tissues. The expression of IL-4 protein expression was not observed in pericarcinoma issues and was extremely low in carcinoma tissues (lane 1, tumor tissue; lane 2, pericarcinoma tissue). Th, T-helper; IFN, interferon; IL, interleukin.

major cytokine arms was evaluated in the context of laryngeal carcinoma. Th1 cells that predominantly express IL-2 and IFN- $\gamma$ enhance cellular cytotoxicity of immune cells, induce delayed type hypersensitivity reactions and are responsible for cell-mediated immunity. By contrast, Th2 cells, which predominantly secrete IL-4, IL-6 and IL-10, are involved with antibody production and the regulation of humoral immune responses. An imbalance in the Th1/Th2 ratio leads to the development of bacterial and viral infections and is involved in allergic disease and autoimmune disorders (38). Previous studies have reported that Th1 responses are suppressed and Th2 responses are elevated systemically in colon cancer, lung cancer and melanoma tumor patients, indicating that Th2 cytokines may mediate immunosuppression (39-42). Th2-mediated immunosuppression reduces protective cellular immunity and is associated with tumor progression (43). It is hypothesized that Th1 cytokines exhibit a protective function, whereas Th2 cytokines favor tumor growth. In the present study, the expression of Th1-associated cytokines was dominant in laryngeal carcinoma patient. Early stage laryngeal carcinoma patients exhibited a higher level of IFN- $\gamma$ and IL-2 mRNA expression than patients at an advanced stage. Cancer tissues exhibited a lower level of IFN- $\gamma$ mRNA expression than pericarcinoma tissues. Cancer tissues also exhibited a significantly lower level of IL-2 mRNA expression than pericarcinoma tissues. The mRNA expression of Th2-associated cytokines was relatively low in laryngeal carcinoma patients. The mRNA expression of IL-4, IL-6 and IL-10 in cancer tissues was higher than in pericarcinoma tissues, however, no significant differences were identified. We hypothesize that in laryngeal carcinoma, the expression of Th2-associated cytokines is inhibited due to the production of Th1-associated cytokines, particularly at the early clinical stage of the disease, which may explain the increased immune response against tumors observed in these patients. The results of the present study were consistent with those of a report on supracricoid laryngectomy, which showed good management of laryngeal cancer $(44,45)$.
Furthermore, Th17 cells that predominantly produce the IL-17 family of cytokines, have gained attention as a novel subset of $\mathrm{T}$ cells in the field of tumor biology, however, its specific function remains unclear (37). IL-17 has been reported to exhibit various effects on tumor progression. Certain studies have indicated that Th17 cells are involved in tissue inflammation via the induction of IL-8, IL-6, cyclooxygenase-2, matrix metalloproteinase (MMP)-1, MMP-3, CXCL1 and nitric oxide synthase- 2 release by surrounding cells, such as fibroblasts, macrophages, endothelial and epithelial cells $(46,47)$, which are involved in angiogenesis, tumor proliferation (48), invasion and metastasis $(49,50)$. By contrast, other studies have reported Th17 cells exhibit an inhibitory influence on tumor growth $(51,52)$. Muranski et al $(53)$ reported that Th17 cells eradicated melanoma in a mouse model. Cirée et al (54) demonstrated that IL-17 is upregulated in the T cell lymphomas, mycosis fungoides and Sézary syndrome, and may act as a tumor growth-promoting or -inhibiting factor. In addition, the authors revealed an association between IL-17 expression and polymorphonuclear neutrophil infiltration. This association was also confirmed by Garcia-Hernandez Mde et al (55), who demonstrated that neutrophils were attracted to the tumor milieu by an IL-17-dependent mechanism and that the depletion of neutrophils resulted in a diminished capacity to control tumor growth. Furthermore, Honorati et al (56) reported that IL-17 increased the susceptibility of osteosarcoma cells to NK cell lysis. It is hypothesized that Th17 cell infiltration is a common characteristic of malignant tumors. In the present study, it was found that patients with early stage laryngeal carcinoma exhibited higher levels of IL-17A mRNA expression than those at advanced stages. Cancer tissues exhibited a significantly higher level of IL-17A mRNA expression than pericarcinoma tissues. Thus, these results indicate that laryngeal cancer patients who exhibit a high expression of Th17-associated cytokines in the tumor microenvironment exhibit a relatively good prognosis.

In the present study, the association between cytokine levels and the clinicopathological characteristics of laryngeal carcinoma patients was investigated. The results indicated 
that male patients ( $>50$ years) are more susceptible to laryngeal cancer development. However, tumor size, lymph node metastasis and pathological classification were not associated with the expression levels of Th1-, Th2- and Th17-associated cytokines. This may be due to the fact that the majority of patients exhibited advanced stage disease. The present study was limited by the sample size; in particular, the number of early stage (I + II) laryngeal carcinoma patients was small. Thus, future studies involving larger sample sizes are required.

In conclusion, the present study revealed a marked shift towards Th1 (IFN- $\gamma$ and IL-2) and Th17 (IL-17A) cytokines in laryngeal cancer patients, particularly at the early clinical stage of the disease. Elevated mRNA and protein expression of Th1 and Th17-cytokines was associated with lower clinical stages, while Th2-associated cytokines were more commonly expressed at advanced stages of the disease. The expression levels of Th1 cytokines in cancer tissues were lower than in pericarcinoma tissues, however, the Th17 cytokines were higher in cancer tissues than pericarcinoma tissues. These results may aid with the development of potential biomarkers with high sensitivities and specificities for the treatment of laryngeal carcinoma. The detection of Th1-, Th2- and Th17-associated cytokines may be used to analyze the pathogenesis of laryngeal neoplasms. The results of the present study indicate that Th1, Th2 and Th17 lymphocyte differentiation may exhibit a critical function in the tumor microenvironment, suggesting that adoptive immunotherapy may be developed via modulation of the T-cell population in the future.

\section{Acknowledgements}

The present study was supported by the National Natural Science Foundation of China (grant no. 81202314), the Natural Science Foundation of Shandong Province (grant no's. ZR2013HL028, ZR2014HQ030 and ZR2010CM067), Shandong Province Outstanding Young Scientist Award Fund (grant no. BS2009SW007), the Special Research Foundation of Large Scientific Instruments on Upgrading and Technological Transformation of Shandong Province (grant no. 2013SJGZ09) and the Seed Foundation of the Second Hospital of Shandong University (grant no. S2013010021).

\section{References}

1. Tosolini M, Kirilovsky A, Mlecnik B, Fredriksen T, Mauqer S Bindea $G$, Berger A, Bruneval P, Fridman WH, Pagès F and Galon J: Clinical impact of different classes of infiltrating T cytotoxic and helper cells (Th1, Th2, Treg, Th17) in patients with colorectal cancer. Cancer Res 71: 1263-1271, 2011.

2. Rajput $S$ and Wilber A: Roles of inflammation in cancer initiation, progression, and metastasis. Front Biosci (Schol Ed) 2: $176-183,2010$.

3. Li W, Chen C, Saud SM, Geng L, Zhang G, Liu R and Hua B: Fei-Liu-Ping ointment inhibits lung cancer growth and invasion by suppressing tumor inflammatory microenvironment. BMC Complement Altern Med 14: 153, 2014.

4. Bierie B and Moses HL: Transforming growth factor beta (TGF-beta) and inflammation in cancer. Cytokine Growth Factor Rev 21: 49-59, 2010

5. Deng S, Hu B, Shen KP and Xu L: Inflammation, macrophage in cancer progression and chinese herbal treatment. J Basic Clin Pharm 3: 269-272, 2012.

6. Su Z, Sun Y, Zhu H, Liu Y, Lin X, Shen H, Chen J, Xu W and Xu H: Th17 cell expansion in gastric cancer may contribute to cancer development and metastasis. Immunol Res 58: 118-124, 2014.
7. Mantovani A, Allavena P, Sica A and Balkwill F: Cancer-related inflammation. Nature 454: 436-444, 2008.

8. Zhu J and Paul WE: Heterogeneity and plasticity of T helper cells. Cell Res 20: 4-12, 2010

9. Hirahara K, Ghoreschi K, Laurence A, Yang XP, KannoY and O'Shea JJ: Signal transduction pathways and transcriptional regulation in Th17 cell differentiation. Cytokine Growth Factor Rev 21: 425-434, 2010.

10. Wei H, Sun R, Xiao W, Feng J, Zheng C, Xu X and Tian Z: Type two cytokines predominance of human lung cancer and its reverse by traditional Chinese medicine TTMP. Cell Mol Immunol 1: 63-70, 2004.

11. Dong C: Diversification of T-helper-cell lineages: Finding the family root of IL-17-producing cells. Nat Rev Immunol 6: 329-333, 2006.

12. Bettelli E, Carrier Y, Gao W, Korn T, Strom TB, Oukka M, Weiner HL and Kuchroo VK: Reciprocal developmental pathways for the generation of pathogenic effector TH17 and regulatory T cells. Nature 441: 235-238, 2006.

13. Yang XO, Pappu BP, Nurieva R, Akimzhanov A, Kang HS Chung Y, Ma L, Shah B, Panopoulos AD, Schluns KS, et al: $\mathrm{T}$ helper 17 lineage differentiation is programmed by orphan nuclear receptors ROR alpha and ROR gamma. Immunity 28 : 29-39, 2008.

14. Ouyang W, Kolls JK and Zheng Y: The biological functions of T helper 17 cell effector cytokines in inflammation. Immunity 28 : 454-467, 2008

15. Maruyama T, Kono K, Mizukami Y, Kawaguchi Y, Mimura K, Watanabe M, Izawa S and Fujii H: Distribution of Th17 cells and FoxP3(+) regulatory $\mathrm{T}$ cells in tumor-infiltrating lymphocytes, tumor-draining lymph nodes and peripheral blood lymphocytes in patients with gastric cancer. Cancer Sci 101: 1947-1954, 2010.

16. Gaur P, Singh AK, Shukla NK and Das SN: Inter-relation of Th1, Th2, Th17 and Treg cytokines in oral cancer patients and their clinical significance. Hum Immunol 75: 330-337, 2014.

17. Wrzesinski SH, Wan YY and Flavell RA: Transforming growth factor-beta and the immune response: Implications for anticancer therapy. Clin Cancer Res 13: 5262-5270, 2007.

18. Jakowlew SB: Transforming growth factor-beta in cancer and metastasis. Cancer Metastasis Rev 25: 435-457, 2006.

19. Chu EA and Kim YJ: Laryngeal cancer: Diagnosis and preoperative work-up. Otolaryngol Clin North Am 41: 673-695 2008.

20. Starmer HM, Tippet DC and Webster KT: Effects of laryngeal cancer on voice and swallowing. Otolaryngol Clin North Am 41: 793-818, 2008

21. Karatzanis AD, Psychogios G, Waldfahrer F, Kapsreiter M, Zenk J, Velegrakis GA and Iro H: Management of locally advanced laryngeal cancer. J Otolaryngol Head Neck Surg 43: 4, 2014.

22. Jemal A, Bray F, Center MM, Ferlay J, Ward E and Forman D: Global cancer statistics. CA Cancer J Clin 61: 69-90, 2011.

23. Lee KJ (ed): Essential Otolaryngology Head and Neck Surgery. 7th edition. McGraw-Hill Medical Publishing Division, New York, 1999

24. Chen XM, Xu XQ, Sun K, Hallett WH, Zhao JD and Zhang DL: NKG2D ligands expression and NKG2D-mediated cytotoxicity in human laryngeal squamous carcinoma cells. Scand J Immunol 67: 441-447, 2008.

25. Tian Z, Shen X, Feng H, Gao B: IL-1 beta attenuates IFN-alpha beta-induced antiviral activity and STAT1 activation in the liver involvement of proteasome-dependent pathway. J Immunol 165: 3959-3965, 2000.

26. Maarof G, Bouchet-Delbos L, Gary-Gouy H, Durand-Gasselin I, Krzysiek R and Dalloul A: Interleukin-24 inhibits the plasma cell differentiation program in human germinal center B cells. Blood 115: 1718-1726, 2010.

27. Jemal A, Siegel R, Xu J and Ward E: Cancer statistics, 2010. CA Cancer J Clin 60: 277-300, 2010.

28. Jaseviciene L, Gurevicius R, Obelenis V, Cicenas S and Juozulynas A: Trends in laryngeal cancer incidence in Lithuania: A future perspective. Int J Occup Med Environ Health 17: 473-477, 2004.

29. Lu ST, Wei KR, Yu BH, Chen Z, Liang Z, Fang F and Zheng WB: Analysis of laryngeal cancer incidence rate in Zhongshan City in 1970-1999. Xian Dai Zhong Liu Yi Xue 12: 158-160, 2004.

30. Hoffman HT, Porter K, Karnell LH, Cooper JS, Weber RS, Langer CJ, Ang KK, Gay G, Stewart A and Robinson RA: Laryngeal cancer in the United States: Changes in demographics, patterns of care, and survival. Laryngoscope 116 (9 Pt 2 Suppl 111): S1-S13, 2006. 
31. Gourin CG, Conger BT, Sheils WC, Bilodeau PA, Coleman TA and Porubsky ES: The effect of treatment on survival in patients with advanced laryngeal carcinoma. Laryngoscope 119: $1312-1317,2009$

32. Hashibe M, Boffetta $P$, Zaridze D, Shangina O Szeszenia-Dabrowska N, Mates D, Fabiánová E, Rudnai P and Brennan P: Contribution of tobacco and alcohol to the high rates of squamous cell carcinoma of the supraglottis and glottis in Central Europe. Am J Epidemiol 165: 814-820, 2007.

33. Shangina O, Brennan P, Szeszenia-Dabrowska N, Mates D, Fabiánová E, Fletcher T, t'Mannetje A, Boffetta P and Zaridze D: Occupational exposure and laryngeal and hypopharyngeal cancer risk in Central and eastern Europe. Am J Epidemiol 164 367-375, 2006.

34. Ma L, Liang Y, Fang M, Guan Y, Si Y, Jiang F, and Wang F: The cytokines (IFN-gamma, IL-2, IL-4, IL-10, IL-17) and Treg cytokine (TGF-betal) levels in adults with immune thrombocytopenia. Pharmazie 69: 694-697, 2014.

35. Li P, Spolski R, Liao W and Leonard WJ: Complex interactions of transcription factors in mediating cytokine biology in T cells. Immunol Rev 261: 141-156, 2014.

36. Ma W, Wang K, Du J, Luan J and Lou G: Multi-dose parecoxib provides an immune protective effect by balancing $\mathrm{T}$ helper 1 (Th1), Th2, Th17 and regulatory T cytokines following laparoscopy in patients with cervical cancer. Mol Med Rep 11: 2999-3008, 2015.

37. Murugaiyan G and Saha B: Protumor vs antitumor functions of IL-17. J Immunol 183: 4169-4175, 2009.

38. Mosmann TR and Sad S: The expanding universe of T-cell subsets: Th1, Th2 and more. Immunol Today 17: 138-146, 1996.

39. Yamamura M, Modlin RL, Ohmen JD and Moy RL: Loca expression of antiinflammatory cytokines in cancer. J Clin Invest 91: 1005-1010, 1993.

40. Oshikawa K, Yanagisawa K, Ohno S, Tominaga S and Sugiyama Y: Expression of ST2 in helper T lymphocytes of malignant pleural effusions. Am J Respir Crit Care Med 165: 1005-1009, 2002.

41. Chen YM, Yang WK, Whang-Peng J, Tsai CM and Perng RP: An analysis of cytokine status in the serum and effusions of patients with tuberculous and lung cancer. Lung Cancer 31: 25-30, 2001.

42. Kharkevitch DD, Seito D, Balch GC, Maeda T, Balch CM and Itoh K: Characterization of autologous tumor-specific T-helper 2 cells in tumor-infiltrating lymphocytes from a patient with metastatic melanoma. Int J Cancer 58: 317-323, 1994.

43. Chtanova T and Mackay CR: T cell effector subsets: Extending the Th1/Th2 paradigm. Adv Immunol 78: 233-266, 2001.

44. Farrag TY, Koch WM, Cummings CW, Goldenberg D Abou-Jaoude PM, Califano JA, Flint PW, Webster K and Tufano RP: Supracricoid laryngectomy outcomes: The Johns Hopkins experience. Laryngoscope 117: 129-132, 2007.
45. Page C, Mortuaire G, Mouawad F, Ganry O, Darras J, Pasquesoone $\mathrm{X}$ and Chevalier D: Supracricoid laryngectomy with cricohyoidoepiglottopexy (CHEP) in the management of laryngeal carcinoma: Oncologic results. A 35-year experience. Eur Arch Otorhinolaryngol 270: 1927-1932, 2013.

46. Agarwal S, Misra R and Aggarwal A: Interleukin 17 levels are increased in juvenile idiopathic arthritis synovial fluid and induce synovial fibroblasts to produce proinflammatory cytokines and matrix metalloproteinases. J Rheumatol 35: 515-519, 2008.

47. Gu Y, Hu X, Liu C, Qv X and Xu C: Interleukin (IL)-17 promotes macrophages to produce IL-8, IL-6 and tumour necrosis factor-alpha in aplastic anaemia. Br J Haematol 142: 109-114, 2008.

48. Numasaki M, Watanabe M, Suzuki T, Takahashi H, Nakamura A, McAllister F, Hishinuma T, Goto J, Lotze MT, Kolls JK and Sasaki H: IL-17 enhances the net angiogenic activity and in vivo growth of human non-small cell lung cancer in SCID mice through promoting CXCR-2-dependent angiogenesis. J Immunol 175: 6177-6189, 2005 .

49. Nabeshima K, Inoue T, Shimao Y and Sameshima T: Matrix metalloproteinases in tumor invasion: Role for cell migration. Pathol Int 52: 255-264, 2002.

50. Li A, Dubey S, Varney ML, Dave BJ and Singh RK: IL-8 directly enhanced endothelial cell survival, proliferation and matrix metalloproteinases production and regulated angiogenesis. J Immunol 170: 3369-3376, 2003.

51. Nam JS, Terabe M, Kang MJ, Chae H, Voong N, Yang YA, Laurence A, Michalowska A, Mamura M, Lonning S, et al: Transforming growth factor beta subverts the immune system into directly promoting tumor growth through interleukin-17. Cancer Res 68: 3915-3923, 2008.

52. Kryczek I, Wei S, Szeliga W, Vatan L and Zou W: Endogenous IL-17 contributes to reduced tumor growth and metastasis. Blood 114: 357-359, 2009

53. Muranski P, Boni A, Antony PA, Cassard L, Irvine KR, Kaiser A, Paulos CM, Palmer DC, Touloukian CE, Ptak K, et al: Tumor-specific Th17-polarized cells eradicate large established melanoma. Blood 112: 362-373, 2008

54. Cirée A, Michel L, Camilleri-Bröet S, Jean Louis F, Oster M, Flageul B, Senet P, Fossiez F, Fridman WH, Bachelez H and Tartour E: Expression and activity of IL-17 in cutaneous T-cell lymphomas (mycosis fungoides and Sezary syndrome). Int J Cancer 112: 113-120, 2004.

55. Garcia-Hernandez Mde L, Hamada H, Reome JB, Misra SK, Tighe MP and Dutton RW: Adoptive transfer of tumor-specific Tc17 effector T cells controls the growth of B16 melanoma in mice. J Immunol 184: 4215-4227, 2010.

56. Honorati MC, Neri S, Cattini L and Facchini A: IL-17 enhances the susceptibility of U-2 OS osteosarcoma cells to NK cell lysis. Clin Exp Immunol 133: 344-349, 2003. 